\title{
Comparison of the effects of general and local anesthesia in lumbar interlaminar endoscopic surgery
}

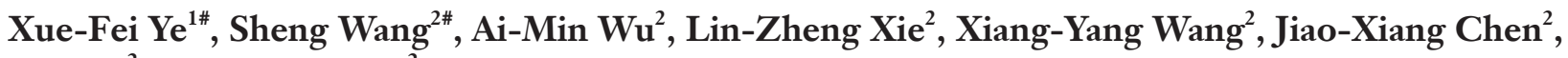 \\ Hui $\mathrm{Xu}^{2}$, Sun-Ren Sheng ${ }^{2}$
}

${ }^{1}$ Department of Anesthesiology, ${ }^{2}$ Department of Orthopaedic Surgery, The Second Affiliated Hospital and Yuying Children's Hospital of Wenzhou Medical University, Wenzhou 325027, China

Contributions: (I) Conception and design: SR Sheng; (II) Administrative support: XF Ye; (III) Provision of study materials or patients: AM Wu; (IV) Collection and assembly of data: LZ Xie; (V) Data analysis and interpretation: XY Wang, H Xu; (VI) Manuscript writing: All authors; (VII) Final approval of manuscript: All authors.

"These authors contributed equally to this work.

Correspondence to: Sun-Ren Sheng. Department of Orthopaedic Surgery, The Second Affiliated Hospital and Yuying Children's Hospital of Wenzhou Medical University, Wenzhou 325027, China. Email: shengsunren82330@126.com.

\begin{abstract}
Background: Percutaneous endoscopic lumbar discectomy (PELD) with an interlaminar approach is a technique used to treat lumbar disc hernia. It has not yet been established whether general or local anesthesia (LA) is preferable for lumbar interlaminar endoscopic surgery.

Methods: Between October, 2012 and June, 2016, 60 patients were recruited and randomly divided into 2 groups: the general anesthesia (GA) group and the LA group. The patients' basic clinical data, intraoperative patient experience, Oswestry disability index (ODI), visual analog scale (VAS) score, and the postoperative patient satisfaction rate were assessed.

Results: Statistically significant differences were found between the two groups in operative time and length of hospital stay. There were no significant differences in postoperative ODI or VAS scores between the two groups during follow-up at 3, 6, and 12 months. One patient in the GA group sustained a nerve root injury intraoperatively. Two patients in the LA group suffered adverse reactions, as did six patients in the GA group. However, $50 \%$ of the patients expressed fear about undergoing the surgery with LA, while all patients felt they could undergo the same surgery with GA.
\end{abstract}

Conclusions: General and LA are both suitable for use in lumbar interlaminar endoscopic surgery. However, GA makes a positive intraoperative surgical experience more likely for the patient.

Keywords: Local anesthesia (LA); general anesthesia (GA); lumbar interlaminar endoscopic surgery; effect

Submitted Feb 10, 2020. Accepted for publication May 06, 2020.

doi: $10.21037 /$ apm-20-623

View this article at: http://dx.doi.org/10.21037/apm-20-623

\section{Introduction}

Percutaneous endoscopic lumbar discectomy (PELD) is a standard technique for the treatment of lumbar disc herniation (1-5). In the late 1990s, the interlaminar approach to PELD started to grow in popularity (1,3-6). Both general anesthesia (GA) and local anesthesia (LA) allow endoscopic surgeries, including PELD, to be safely performed (7-9). LA is recommended by most surgeons for PELD because of its rapid onset and lower risk of nerve injury and pulmonary complications, as well as its ability to prevent pressure necrosis, reduce intraoperative blood loss, and provide proper postoperative pain control (2-6). Nevertheless, the use of LA for percutaneous interlaminar endoscopic discectomy is not without complications and can result in nerve root injury, dural tear, hematoma, and intracranial hypertension (10).

Patient satisfaction and the ability of surgeon to perform prolonged operations are two of the main advantages with 
GA. Desirable intraoperative hemodynamic conditions, including minimal blood transfusion, the earliest possible discharge from the postanesthesia care unit (PACU), and reduced incidence of common postoperative problems, such as pain, analgesic consumption, nausea, and vomiting, are important elements of good anesthesia (11-13). For these advantages, some surgeons prefer GA for percutaneous endoscopic discectomy with an interlaminar approach $(8,9)$.

Controversy still surrounds the feasibility, safety, and efficacy of LA and GA for patients undergoing lumbar interlaminar endoscopic surgery. However, modern GA techniques, such as multimodal nonopioid analgesia and a fast-track approach, have not often been compared with LA. Therefore, this study set out to determine which type of anesthesia has better clinical outcomes.

We present the following article in accordance with the CONSORT reporting checklist (available at http://dx.doi. org/10.21037/apm-20-623).

\section{Methods}

Between October, 2012 and June, 2016, patients diagnosed with lumbar intervertebral disc were recruited for this study at our hospital. In all, 65 consecutive patients were assessed for eligibility by 2 surgeons, and 60 were finally included after a preoperative visit by an anesthetist [Figure 1 (CONSORT flow diagram)].

The patients were enrolled according to a relatively narrow set of inclusion and exclusion criteria. The inclusion criteria were as follows: (I) diagnosis of lumbar intervertebral disc with one or two contiguous lumbar levels; (II) levels between L4 and S1 affected; and (III) symptoms consistent with the pathology (typically radiculopathy, with or without back pain). Prior lumbar fusion surgery, extreme lateral lumbar disc herniation, spinal metastases or active spinal tumor malignancy, and active local or systemic infection, were the primary reasons for exclusion.

The study received approval from the Research Ethics Committee of The Second Affiliated Hospital and Yuying Children's Hospital of Wenzhou Medical University. All patients provided written informed consent before undergoing surgery.

The surgeries were performed by two experienced surgeons who had carried out 200 PELD procedures over 4 years. The patients were randomly divided into two groups according to a blinded allocation card at each site. Thirty patients underwent GA administered by an anesthesiologist, and the other 30 patients underwent surgery with LA administered by the surgeon. No local anesthetic was administered to the patients who underwent GA. The patients were followed-up for more than 12 months after the surgery.

\section{Anesthesia methods}

The LA group received $0.5 \%$ lidocaine in $10 \mathrm{~mL}$, and $0.25 \%$ ropivacaine at $1.3 \mathrm{mg} / \mathrm{kg}$ was administered to prevent related pain. In the GA group, propofol $2-3 \mathrm{mg} / \mathrm{kg}$, sufentanil $0.2 \mu \mathrm{g} / \mathrm{kg}$, and cisatracurium $0.2 \mathrm{mg} / \mathrm{kg}$ were administered to facilitate endotracheal intubation, and ventilation was controlled to maintain the end-tidal carbon dioxide $\left(\mathrm{CO}_{2}\right)$ between 32-38 mmHg. To maintain anesthesia, 2-3\% sevoflurane kept the bispectral index (BIS) between 40 and 60 , and $0.05 \mathrm{mg} / \mathrm{kg}$ of the muscle relaxant cisatracurium was added at 40-minute intervals according to the conditions of the operation. No other medication was administered.

\section{Evaluation criteria}

The length of hospital stay, operative time (length of time in the operating theater), and intraoperative pain rates were recorded. Adverse reactions within $24 \mathrm{~h}$ after surgery, postoperative patient satisfaction rates, and neurological complications were assessed. Visual analog scale (VAS) score and the Oswestry disability index (ODI) were assessed at 3, 6 , and 12 months postoperatively.

\section{Statistical analysis}

The measurement data are expressed as the mean \pm standard deviation. Differences among measurement data were statistically analyzed by Student's $t$-test. Enumerated data are expressed as percentages and were compared by the chisquare test. Statistical significance was considered to exist when $\mathrm{P}<0.05$.

\section{Results}

There were no significant differences in the baseline values between the two groups. However, the mean operative time in the LA group was lower than in the GA group $(50.12 \pm 23.65$ and $78.64 \pm 19.12 \mathrm{~min}$, respectively; $\mathrm{P}<0.01)$. Length of hospital stay was shorter in the LA group ( $3.3 \pm 0.47$ days) than in the GA group ( $4.7 \pm 0.96$ days) 


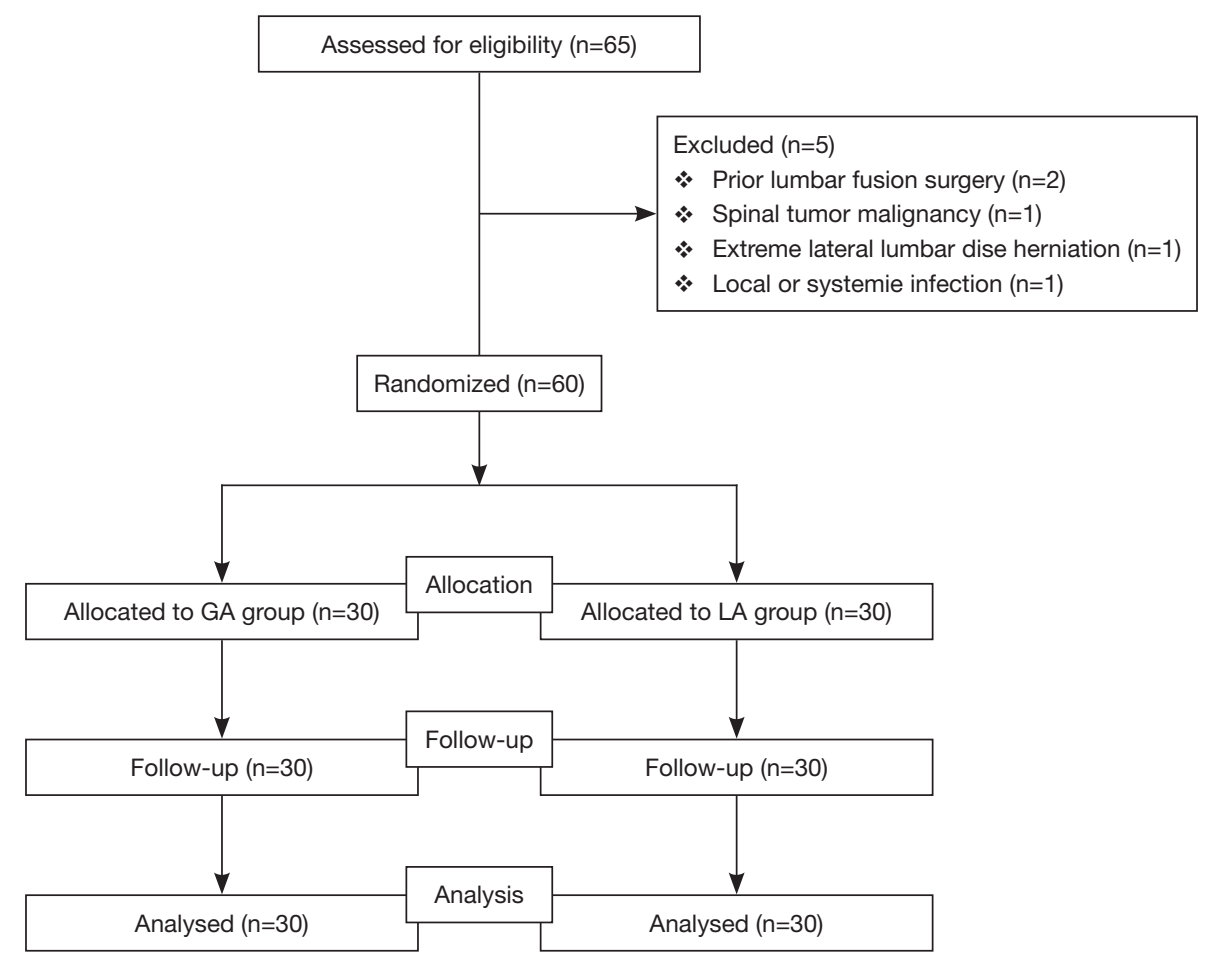

Figure 1 Consort flow diagram for the study.

Table 1 The baselines and operative data of the two groups

\begin{tabular}{lccc}
\hline Baseline and operative data & Local anesthesia No. $=30$ & General anesthesia No. $=30$ & $\mathrm{t}$ \\
\hline Sex (male/female) & $17 / 13$ & $16 / 14$ & 0.21 \\
Age (years) & $42.14 \pm 4.25$ & $43.68 \pm 4.43$ & 1.25 \\
Central LDH & 13 & 14 & 16 \\
Lateral LDH & 17 & $4.7 \pm 0.96$ & -6.548 \\
Hospital stay (days) & $3.3 \pm 0.47$ & $78.64 \pm 19.12$ & 0.000 \\
Operative time (min) & $50.12 \pm 23.65$ & & -4.688 \\
\hline
\end{tabular}

$\mathrm{LDH}$, lumbar disc herniation.

(Table 1).

In the LA group, none of the patients suffered cauda equina nerve or nerve root injury. Half of the patients (50\%) feared receiving the surgery with LA, while all patients were willing to undergo the same surgery under GA. In the GA group, one patient suffered nerve root injury intraoperatively. Three months after nutrition and rehabilitation treatment, the patient's muscle strength had recovered from grade 2 to grade 4 . Adverse reactions were experienced by $8 \%(2 / 30)$ of the patients in the LA group and $18 \%(6 / 30)$ of the patients in the GA group (Table 2).
As shown in Figure 2, the postoperative ODI and VAS scores decreased $(\mathrm{P}<0.05)$ from 3 months postoperative to 12 months postoperative. However, there were no significant differences between the two groups at the 3-, 6and 12-month postoperative follow-up time points $(\mathrm{P}>0.05)$.

\section{Discussion}

In recent years, LA has been established as an effective, reliable, and successful alternative to GA for lumbar surgery (14-16). Due to the sensory blockade applied in GA, cauda 
Table 2 Comparison of adverse reactions, patient feeling between the local group and the general group

\begin{tabular}{|c|c|c|c|}
\hline Adverse reactions and patient satisfaction & Local anesthesia $(n=30)$ & General anesthesia $(n=30)$ & $\mathrm{P}$ \\
\hline Vomiting & $3.3 \%(1 / 30)$ & $0(0 / 30)$ & 0.321 \\
\hline Dizziness & $0(0 / 30)$ & $6.6 \%(2 / 30)$ & 0.155 \\
\hline Drowsiness & $0(0 / 30)$ & $6.6 \%(2 / 30)$ & 0.155 \\
\hline Fear to undergo the same surgery with same anesthesia & $50 \%(15 / 30)$ & $0(0 / 30)$ & 0.000 \\
\hline
\end{tabular}

A

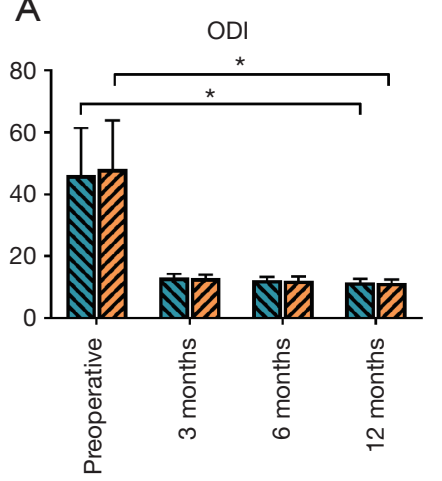

B

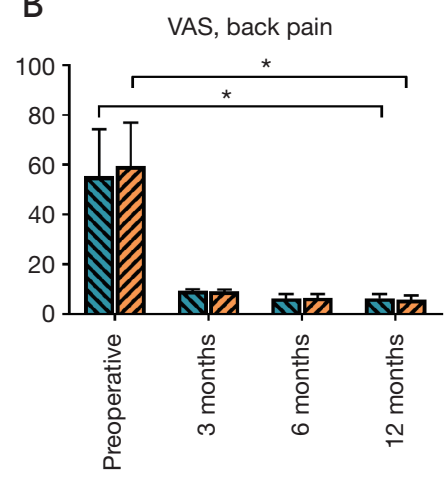

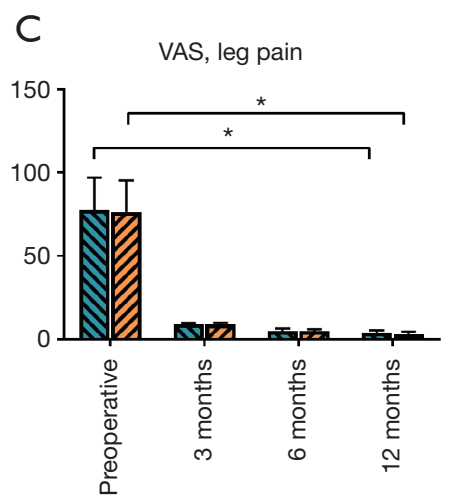

Local anesthesia

General anesthesia

Figure 2 Comparison of ODI, VAS between the local group and the general group. ODI, Oswestry disability index; VAS, visual analog scale. *, $\mathrm{P}<0.05$.

equina nerve and nerve root injury are difficult to detect. For these reasons, most surgeons, especially those with less experience, prefer LA.

Nevertheless, LA had disadvantages: operative anxiety and anesthesia-induced stress reactions, immune suppression, and inflammatory reactions (17). Wang found that continuous epidural anesthesia had more advantages than LA in improving the immune function of patients undergoing PELD for lumbar intervertebral disc herniation and proposed that painless surgery would reduce the adverse psychological effects, such as postoperative anxiety (18). In this study, $66.66 \%(20 / 30)$ of patients felt pain intraoperatively, and 6 patients (6/30) felt unbearable pain in the LA group. Therefore, the patients in the GA group had better immune suppression and inflammatory reactions than those in the LA group. In modern society, more attention is paid to patients' intraoperative psychology. Surgical experience (19-21) is becoming increasingly important as good surgical experiences are associated with good postoperative clinical results. In the LA group, 15 patients feared undergoing reoperation, but no patients in the GA group feared undergoing reoperation, which indicates that the patients in the GA group had better surgical experiences.

Compared with the LA group, the GA group had longer operative times and hospital stays. However, the differences between the groups were only half an hour and one day, respectively, and can possibly be attributed to preparation time for GA and recovery time from tracheal intubation. Adverse reactions, VAS scores, ODIs, postoperative patient satisfaction rates, and neurological complications were similar between the two groups. Thus, there were no significant differences between the clinical results of the two groups.

There is a learning curve associated with endoscopic techniques. After at least 72 surgical procedures, 90\% of cases have good/excellent results (22). In this study, one patient in the GA group sustained nerve root injury. Electromyography (EMG) could assist skilled surgeons in reducing nerve root injury during lumbar interlaminar 
endoscopic surgery with GA.

This study had some limitations that need to be addressed. Firstly, only lumbar interlaminar endoscopic surgery was evaluated. Secondly, the study lacks large sample size calculations and long follow-up times. Further research with larger sample sizes and longer follow-up time is required.

\section{Conclusions}

GA and LA are both effective for lumbar interlaminar endoscopic surgery. However, GA makes a positive intraoperative surgical experience more likely for the patient.

\section{Acknowledgments}

Funding: This work was supported by Basic Public Welfare Project of Zhejiang Province (No. LGF19H060008) and Wenzhou Bureau of Science and Technology Project (No: 2018Y1551).

\section{Footnote}

Reporting Checklist: The authors have completed the CONSORT reporting checklist. Available at http://dx.doi. org/10.21037/apm-20-623

Data Sharing Statement: Available at http://dx.doi. org/10.21037/apm-20-623

Conflicts of Interest: All authors have completed the ICMJE uniform disclosure form (available at http://dx.doi. org/10.21037/apm-20-623). The authors have no conflicts of interest to declare.

Ethical Statement: The authors are accountable for all aspects of the work in ensuring that questions related to the accuracy or integrity of any part of the work are appropriately investigated and resolved. This study was approved by The Second Affiliated Hospital and Yuying Children's Hospital of Wenzhou Medical University Research Ethics Committee Meeting (No. LCKY2019-287).

Open Access Statement: This is an Open Access article distributed in accordance with the Creative Commons Attribution-NonCommercial-NoDerivs 4.0 International License (CC BY-NC-ND 4.0), which permits the non- commercial replication and distribution of the article with the strict proviso that no changes or edits are made and the original work is properly cited (including links to both the formal publication through the relevant DOI and the license). See: https://creativecommons.org/licenses/by-nc-nd/4.0/.

\section{References}

1. Lew SM, Mehalic TF, Fagone KL. Transforaminal percutaneous endoscopic discectomy in the treatment of far-lateral and foraminal lumbar disc herniations. J Neurosurg 2001;94:216-20.

2. Matsui H, Aoki M, Kanamori M. Lateral disc herniation following percutaneous lumbar discectomy. A case report. Int Orthop 1997;21:169-71.

3. Ruetten S, Komp M, Godolias G. A New full-endoscopic technique for the interlaminar operation of lumbar disc herniations using 6-mm endoscopes: prospective 2-year results of 331 patients. Minim Invasive Neurosurg 2006;49:80-7.

4. Ruetten S, Komp M, Merk H, et al. Use of newly developed instruments and endoscopes: full-endoscopic resection of lumbar disc herniations via the interlaminar and lateral transforaminal approach. J Neurosurg Spine 2007;6:521-30.

5. Liu Y, Wang S, Yang C, et al. Retrospective study of the interlaminar approach for percutaneous endoscopic lumbar discectomy with the guidance of pre-operative magnetic resonance neurography. Ann Transl Med 2019;7:145.

6. Destandau J. A special device for endoscopic surgery of lumbar disc herniation. Neurol Res 1999;21:39-42,.

7. Chen HT, Tsai CH, Chao SC, et al. Endoscopic discectomy of L5-S1 disc herniation via an interlaminar approach: Prospective controlled study under local and general anesthesia. Surg Neurol Int 2011;2:93.

8. Sairyo K, Egawa H, Matsuura T, et al. State of the art: Transforaminal approach for percutaneous endoscopic lumbar discectomy under local anesthesia. J Med Invest 2014;61:217-25.

9. Suess O, Brock M, Kombos T. Motor nerve root monitoring during percutaneous transforaminal endoscopic sequestrectomy under general anesthesia for intra- and extraforaminal lumbar disc herniation. Zentralbl Neurochir 2005;66:190-201.

10. Sairyo K, Matsuura T, Higashino K, et al. Surgery related complications in percutaneous endoscopic lumbar discectomy under local anesthesia. J Med Invest 2014;61:264-9. 
11. Hassi N, Badaoui R, Cagny-Bellet A, et al. Spinal anesthesia for disk herniation and lumbar laminectomy. Apropos of 77 cases. Cah Anesthesiol 1995;43:21-5.

12. Riegel B, Alibert F, Becq MC, et al. Lumbar disk herniation with surgical option: general versus local anesthesia. Round table. Agressologie 1994;34 Spec No $1: 33-7$.

13. Edgcombe H, Carter K, Yarrow S. Anaesthesia in the prone position. Br J Anaesth 2008;100:165-83.

14. Demirel CB, Kalayci M, Ozkocak I, et al. A prospective randomized study comparing perioperative outcome variables after epidural or general anesthesia for lumbar disc surgery. J Neurosurg Anesthesiol 2003;15:185-92.

15. Fernández-Ordóñez M, Tenías JM, Picazo-Yeste J. Spinal anesthesia versus general anesthesia in the surgical treatment of inguinal hernia. Cost-effectiveness analysis). Rev Esp Anestesiol Reanim 2014;61:254-61.

16. Nicassio N, Bobicchio P, Umari M, et al. Lumbar microdiscectomy under epidural anaesthesia with the patient in the sitting position: a prospective study. J Clin Neurosci 2010;17:1537-40.

Cite this article as: Ye XF, Wang S, Wu AM, Xie LZ, Wang XY, Chen JX, Xu H, Sheng SR. Comparison of the effects of general and local anesthesia in lumbar interlaminar endoscopic surgery. Ann Palliat Med 2020;9(3):1103-1108. doi: 10.21037/apm20-623
17. Pearson AM, Lurie JD. Surgical versus nonoperative treatment: how do we choose the right approach to lumbar disk herniation? Pain Manag 2014;4:247-9.

18. Wang SJ, Chen BH, Wang P, et al. The effect of percutaneous endoscopic lumbar discectomy under different anesthesia on pain and immunity of patients with prolapse of lumbar intervertebral disc. Eur Rev Med Pharmacol Sci 2017;21:2793-9.

19. Mancuso CA, Duculan R, Stal M, et al. Patients' expectations of lumbar spine surgery. Eur Spine J 2015;24:2362-9.

20. Mancuso CA, Duculan R, Cammisa FP, et al. Fulfillment of patients' expectations of lumbar and cervical spine surgery. Spine J 2016;16:1167-74.

21. Toyone T, Tanaka T, Kato D, et al. Patients' expectations and satisfaction in lumbar spine surgery. Spine (Phila $\mathrm{Pa}$ 1976) 2005;30:2689-94.

22. Morgenstern R, Morgenstern C, Yeung AT. The learning curve in foraminal endoscopic discectomy: experience needed to achieve a 90\% success rate. SAS J 2007;1:100-7. 